cartilage assume, in consequence of their being flattened by the pressure upon the articular surfaces. Still more recently, Dr. Joseph Leidy has published in the American Journal of the Medical Sciences, for April, 1849, some researches into the structure of articular cartilage, of which a digest is given in the London Journal of Medicine, for June, 1849. With respect to the synovial membrane, "Dr. Leidy has always failed to detect this in the adult, on the free surface of the cartilage, or even the appearance of a basement membrane. It appears to terminate at the circumference of the articular cartilage, very little beyond the vascular circle."-London Journal of Medicine, VI. Page 562.

I shall endeavour in this paper, to show that the opinion which is held by English anatomists as well as by most foreign ones, including Valentin and Henlé is correct, and that the synovial membrane can be traced as a continnous layer over the entire surface of the articular cartilage. The Freǹch theory seems to have arisen from the difficulty and almost impossibility which there is in isolating the synovial nembrane, so as to show it as a distinct structure. This difficulty is alluded to in the following short description of this membrane by Todd and Bowman:- A pavement of nucleated epithelial particles has been described by Henle to exist on the free surface of articular cartilage. In the foetus this may be readily seen; but in the adult we have often failed to detect it, even in perfectly fresh specimens and notwithstanding great care. An irregularity of surface often exists and seems to shew that this covering ceases, when the part becomes subject to friction and pressure. Cells, too, are often seen close to this surface, and eren partly projecting from it-appearances indicative of attrition."

I had myself been unable, after several trials, to dissect off the synovial membrane from the articular cartilage as far as its centre, until a short time since, when I was fortunate enough to meet with a subject in whom the membrane was remarkably thick and distinct. The subject was a lad, aged 17, who was dissected at the medical school, and althongh the joints were not diseased, yet the synovial membrane appeared remarkably soft and thick, and of a rosy colour. It was not difficult, by beginning at the circumference of the head of the femur, to detach a thin strip of synovial membrane eren as far as its centre.

Such a strip when examined under the microscope, exhibits but little evidence of structure, its surface is covered here and there with faint lines and creasings, which in some places exhibit a slight appearance of pavement epithelium, but this is by no means distinct. The membrane is so thin and adheres so closely to the surface of the cartilage, that it is rery difficult to detach it without either tearing it, or bringing away a number of adherent cartilage cells. However, in many places it will be found to be quite free from these. On making a vertical section of the articular cartilage from the head of the femur in the sane subject, the synovial membrane appeared under the microscope as a thin but distinct layer, presenting very evident characters of structure. It cun then be seen to be distinctly made up of flattened cells, imbricated one upon the other, their free edges pointing obliquely upwards; some of these, apparently in consequence of friction are partially or almost entirely detached. In an oblique section of the same cartilage these appearances are not seen so clearly, but a distinct line of demarcation can be observed between the synovial membrane and the cartilage it rests upon. In the specimens which I have from the fotus and the infant at birth, the synovial membranes can be shown, but not so distinctly as in former sections; the membrane here appears much smoother on its free surface, and the cells seem to be placed much more flatly upon the cartilage. It is rare also to meet with detached cells. This evidently results from the little amount of friction which the membrane has undergone. Under all circumstances, however, the synovial membrane, when it covers articular cartilage is an exceedingly thin and compact layer, adbering very firmly to the subjucent cartilage, and in most cases it is impossible to detach it as a distinct membrane for more than a quarter or half an inch, at farthest, beyond the edge of the cartilage, and it is chiefly from this circumstance, that the French anatomists above mentioned, believe that a breach in its continuity here takes place; a view, howerer, which is not sanctioned by what we know of the patbology of joints in general.

\section{CASE OF INFANTILE DIABETES.}

\section{By Joshoa Parsons, Esq., M.R.C.S., Beckington,} Somersetshire.

On the 23rd of February, 1848, I was requested to see J. P., aged eleven months, the child of respectable parents, who was represented to me to be near death from decline. On examination I found him in the following condition :-The skin dry, shrivelled, and of uniform purplish hue, below the natural temperature, the extremities especially being very cold; the emaciation was extreme in the trunk and extremities, but the face was puffed, and, especially around the eyes, cedematous; the debility seemed great, and every movement communicated to the infant by the nurse appeared to gire great uneasiness, which was expressed by a low whining cry, at all other times the child lay either in a semi-comatose state, or was continually moaning; the pulse was 96, extremely feeble and thready ; the tongue bore an exact resemblance to the surface of raw beef, being dark, red, and glossy, and so chopped as to mark it out into numerous little square compartments. The similar appearance of this tongue to that of a patient at that time under my care with ordinary diabetes, immediately led me to inquire into the state of the urinary function. I could gain no accurate information respecting the quantity of urine, but the attendants supposed, from the number of napkins required, that it must be greater than usual, and they spontaneously remarked that it had a very strange sinell, which was compared by one to mead, and by another to spoiled honey. I procured about an ounce for examination, and found it to possess the following properties:-The colour nearly as dark as ordinary brandy; smell sickly and sweet; consistence 
thick and viscid; reaction acid, specific gravity 1.044, and yielding on evaporation nearly half its weight of imperfectiy dried solid matter; the alvine secretions were black and scybalous. On inquiry, I found that the child was weaned at two months, after which it became very fretful and restless. To prevent the inconvenience from this source, it was occasionally treated, with what is called in this neighbourhood, "a sugar-teat," i.e., a pinch of moist sugar tied up in rag, and placed in its mouth. This expedient answered so admirably, that the same process was repeated with increasing frequency, until, for some time before my visit, he had consumed in this way from three-quarters to a whole pound of sugar daily, taking no other nutriment, except on rare occasions a draught of milk, sweetened with sugar. Cold water would have been swallowed with avidity at any time, but from the fear of this liquid, so prevalent among the ignorant, was rarely supplied. By way of remedy I suggested, without, I must confess, a hope of success, for the infant seemed to be dying, an immediate abandonment of "sugarteats," the child to be nourished with milk-and-water, alternating with weak animal broths, the thirst to be fully gratified with cold water, and the following medicines given :-R. Potass. Nitrat., gr. xij.; Acid. Nitric., m. iv.; Infus. Aurant., dr. iij.; Aq. Distill., dr. ix. M. Coch., min. j., quartis horis adhibend.-R. Hyd. cum Creta, gr. ij.; Pulv. Aromat., gr. ij. Fiat Pulv., hora somni sumendus.

24th. On my next visit, about eighteen hours after, the child appeared much the same, had passed a much quieter night than was expected, and although the directions respecting medicine, food, and drink, had been scrupulously attended to, the quantity of urine passed was greatly lessened, and none could be procured for inspection. Ordered to persevere, though still with very little expectation of permanent good.

26th. Unaroidable circumstances prevented my seeing the patient on the $25 \mathrm{th}$, but when I called the next morning I could scarcely think I was looking upon the same child. The face was now thin and pale, wearing an easy though faint smile; the limbs warm, and the general temperature and colour of the body natural ; the tongue was paler, the thirst less, and the appetite for wholesome nutriment increasing. The bowels had been considerably purged, five or six motions having been passed, which were first black and semi-solid, but latterly fluid and green; the quantity of urine had again increased, but it had now nearly lost the diabetic character; it was pale, acid, of specific gravity 1.022, and not appreciably sweet, and I could detect no saccharine properties in the solid residuum after evaporation. I can add no more. From this time the infant rapidly improved, and at the end of a month was a fat bealthy child, and has, ever since remained strong and well. It was my intention to have transmitted a specinsen of the urine for strict chemical investigation, but from the circumstances detailed above, I never had an opportunity of procuring another specimen after that which served for my first rough examination; and from the unexpectedly rapid recovery of the little patient, the opportunity was lost for several observations, which hare since suggested themselres.

\section{CASES OF POISONING BY THE ACETATE OF LEAD, WITH REMARKS.}

\author{
By William Norris, M.D., Stourbridge.
}

Acute and chronic diseases of the abdominal viscera form a large class of the most violent and dangerous character that come under the treatment of the medical practitioner, and without early and decisive measures, they too often terminate fatally; and any opportunity that may occur to throw the least additional light on their pathodogy or treatment, should be zealously cultivated. As an awful occurrence has taken place in the towns of Stourbridge and Kidderminster, and the neighbouring villages, from the mistake of a miller's servant, who mixed about thirty pounds of acetate of lead, in the place of alum, with sixty or eighty sacks of flour, nearly a thousand persons haring suffered from its poisonous effects, I shall make a feeble attempt to place before the profession anything new or striking, with the hope that it might induce eminent toxicologists to investigate this alarming disease more minutely. The sufferings of the patients being unusually protracted and serere, in consequence of eating the poisoned bread some weeks after the violent symptoms first commenced, the strongest and most robust men, (from long suffering, and from the frequent occurrence of violent paroxysms,) have been reduced to the most emaciated and feeble state.

The persons who ate the bread, after a few weeks complained of a peculiar taste; some compared it to soda, others to rusty needles or copper. The tongue was covered with a darkish cream.coloured mucus, and was soft and flabby; the gums were swollen, with a blue line on the margin, and in many cases the blue tinge extended nearly over the gums, and occasionally on the inner side of the lower lip, and in a faint degree over the mucous membrane of the mouth and towards the fauces; the tonsils were in some cases enlarged, producing soreness of the throat, and in other cases there was salivation, a clear fluid flowing from the mouth many days after convalescence. These symptoms were accompanied by loss of appetite, nausea, vomiting, flatulency, and obstinate constipation, with a sense of constriction in the throat and epigastrium, and a violent spasmodic pain and twisting around the umbilicus, which was retracted; the pain was sometimes increased by pressure, occasionally extending over the abdomen, and when the paroxysms were riolent, the muscles of the abdomen were contracted spasmodically, and a most frequent symptom was pain in the loins, about the situation of the lumbar fascia, and in the deltoid muscles. The patients were chilly, with great languor and lassitude; the cutaneous secretion was diminished; the intellect was clear, but there was generslly depression of the nervous, sanguineous, and muscular systems; the pulse was low and feeble; the features were sallow, and shrunk; and the muscles felt soft and flabby; the fluid vomited was often mixed with bile, and occasionally coffee-ground secretion; the fæces were dark, and highly offensire, with scybala; the secretion from the kidueys was scanty, and of a dark red colour, almost like porter. 